\title{
Duodenal neuroendocrine tumors: Impact of tumor size and total number of lymph nodes examined
}

\author{
Xu-Feng Zhang MD, PhD ${ }^{1,2}$ (1) | Xiao-Ning Wu MD ${ }^{1}$ | Diamantis I. Tsilimigras $\mathrm{MD}^{2}$ (0) | \\ George Poultsides MD ${ }^{4}$ | Flavio Rocha MD ${ }^{5}$ | Daniel E. Abbott MD ${ }^{6}$ | \\ Ryan Fields $M^{7}$ | Kamran Idrees $M^{8} D^{8}$ | Cliff Cho MD ${ }^{9}$ | Shishir K. Maithel MD ${ }^{3}$ | \\ Timothy M. Pawlik MD, MPH, PhD² | other members of the US Neuroendocrine Tumor \\ Study Group
}

${ }^{1}$ Department of Hepatobiliary, Surgery and Institute of Advanced Surgical Technology and Engineering, The First Affiliated Hospital of Xi'an Jiaotong University, Xi'an, China

${ }^{2}$ Division of Surgical Oncology, The Ohio State University Wexner Medical Center and James Comprehensive Cancer Center, Columbus, $\mathrm{OH}$

${ }^{3}$ Division of Surgical Oncology, Department of Surgery, Winship Cancer Institute, Emory

University, Atlanta, GA

${ }^{4}$ Department of Surgery, Stanford University, Palo Alto, CA

${ }^{5}$ Department of Surgery, Virginia Mason Medical Center, Seattle, WA

${ }^{6}$ Department of Surgery, University of Wisconsin School of Medicine and Public Health, Madison, WI

${ }^{7}$ Department of Surgery, Washington University School of Medicine, St. Louis, WI

${ }^{8}$ Division of Surgical Oncology, Department of Surgery, Vanderbilt University, Nashville, TN

${ }^{9}$ Division of Hepatopancreatobiliary and Advanced Gastrointestinal Surgery, Department of Surgery, University of Michigan, Ann Arbor, MI

\section{Correspondence}

Timothy M. Pawlik, MD, MPH, PhD, FACS

FRACS (Hon.), Professor and Chair,

Department of Surgery, The Urban Meyer III and Shelley Meyer Chair for Cancer Research, Professor of Surgery, Oncology, Health Services Management and Policy, The Ohio State University, Wexner Medical Center, 395 W. 12th Ave., Suite.

Email: tim.pawlik@osumc.edu

\begin{abstract}
Background: The current study sought to investigate the impact of tumor size and total number of LN examined (TNLE) on the incidence of lymph node metastasis (LNM) among patients with duodenal neuroendocrine tumor (dNET).

Methods: Patients who underwent curative resection for dNETs between 1997-2016 were identified from 8 high-volume US centers. Risk factors associated with overall survival and LNM were identified and the optimal cut-off of TNLE relative to LNM was determined.

Results: Among 162 patients who underwent resection of dNETs, median patient age was 59 (interquartile range [IQR], 51-68) years and median tumor size was $1.2 \mathrm{~cm}$ (IQR, 0.7-2.0 cm); a total of $101(62.3 \%)$ patients underwent a concomitant LND at the time of surgery. Utilization of lymphadenectomy (LND) increased relative to tumor size $(\leq 1 \mathrm{~cm}: 52.2 \%$ vs $1-2 \mathrm{~cm}: 61.4 \%$ vs $>2 \mathrm{~cm}: 93.8 \% ; P<.05)$. Similarly, the incidence of LNM increased with dNET size $(\leq 1 \mathrm{~cm}: 40.0 \%$ vs $1-2 \mathrm{~cm}: 65.7 \%$ vs $>2 \mathrm{~cm}: 80.0 \% ; P<.05$ ). TNLE $\geq 8$ had the highest discriminatory power relative to the incidence of LNM (area under the curve $=0.676$ ). On multivariable analysis, while LNM was not associated with prognosis (hazard ratio $[\mathrm{HR}]=0.9 ; 95 \%$ confidence intervals [95\% $\mathrm{Cl}$ ], 0.4-2.3), G2/G3 tumor grade was ( $\mathrm{HR}=1.5 ; 95 \% \mathrm{Cl}, 1.0-2.1)$.

Conclusions: While the incidence of LNM directly correlated with tumor size, patients with dNETs $\leq 1 \mathrm{~cm}$ had a $40 \%$ incidence of LNM. Regional lymphadenectomy of a least $8 \mathrm{LN}$ was needed to stage patients accurately.
\end{abstract}

KEYWORDS

Ampulla, neuroendocrine tumor, Duodenum, prognosis, surgery 


\section{1 | INTRODUCTION}

Duodenal neuroendocrine tumors (dNETs) represent up to $3 \%$ of all primary duodenal malignancies and $2 \%-3 \%$ of all gastrointestinal neuroendocrine tumors (NETs). ${ }^{1-3}$ The incidence of dNETs has increased from $0.027 / 100000$ in 1983 to $1.1 / 100000$ in 2010, perhaps reflecting the increased use of gastrointestinal endoscopy. ${ }^{4,5}$ According to the latest population study in the United States, dNETs present most often in the 6th decade of life and males are slightly more predominant than females. ${ }^{6}$ In turn, resection of dNETs generally represents the most common modality associated with the best chance at cure.

Although dNETs are usually small on presentation (ie, $75 \%$ of cases $\leq 20 \mathrm{~mm}$ ), regional lymph node (LN) metastasis has been reported in up to $40 \%-80 \%$ of cases. ${ }^{7-10}$ Current treatment guidelines recommend treatment strategies for dNETs that are similar to gastric NETs for nonfunctional tumors and similar to pancreatic NETs for functional dNETs. ${ }^{11}$ For example, the European Neuroendocrine Tumor Society (ENETS) consensus guidelines generally recommend surgical treatment for large $(>20 \mathrm{~mm})$ and/or metastatic dNETs, as well as periampullary dNETs. ${ }^{11}$ More often dNET cases are now diagnosed, however, incidentally when the tumors are small in size $(<10 \mathrm{~mm})$, well-differentiated, limited to the mucosa and submucosa, and nonfunctioning. In turn, endoscopic local excision may be increasingly considered for these early-stage tumors rather than surgical resection. ${ }^{12}$ The impact of not staging the nodal basin in the setting of endoscopic excision remains poorly defined. Unfortunately, data on the clinical characteristics, tumor biology, treatment, and prognosis of patients with dNETs have been limited largely to small, single-center case series. ${ }^{12-14}$ Therefore, the objective of the current study was to define the outcomes of patients who underwent curative-intent resection for periampullary and nonampullary dNETs using a large, multi-institutional database. Specifically, the aim was to characterize potential risk factors associated with the presence of lymph node metastasis (LNM), as well as identify the minimal number of LN needed to stage patients optimally.

\section{2 | METHODS}

\subsection{Study cohort and data collection}

Patients who underwent surgical resection for dNETs between 1997 and 2016 were identified from the US Neuroendocrine Tumor Study Group (US-NETSG). ${ }^{15}$ All patients were diagnosed with dNETs, which were confirmed by histological examination. Patients who presented with distant metastasis or underwent cytoreductive/palliative (R2) resection were excluded. The study was approved by the Institutional Review Boards at each participating institution.

A standardized datasheet was utilized to collect the demographic, clinical, and pathologic data at each institution. Largest tumor size, primary tumor location, the total number of LNs examined (TNLE), the number of LNM, perineural invasion, lymphovascular invasion, and surgical margin status were determined based on the final pathological report. The tumors were staged according to the eighth TMN stage scoring system ${ }^{16}$ and classified as grade G1 (Ki-67 $\leq 2 \%$ ), G2 (Ki-67 3\%$20 \%$ ), and G3 (Ki-67 >20\%) according to the WHO 2010 classification. ${ }^{17}$ Overall survival (OS) was calculated from the date of surgery to the date of death or date of last follow-up. Tumor recurrence was determined by suspicious imaging finding or biopsy-proven tumor.

\section{2 | Statistical analysis}

Categorical variables were reported as totals and percentages and compared by $\chi^{2}$ test or Fisher exact test as appropriate. Continuous variables were expressed as median with interquartile ranges (IQRs) and compared using the Mann-Whitney $U$ test. Kaplan-Meier survival curves were plotted and compared using the logrank test. The receiveroperating characteristic curve analysis was used to investigate the discriminatory ability of TNLE relative to the number of LNM. Risk factors associated with OS or LNM were identified by using Coxproportional hazard regression models or Logistic regression models, respectively. Results were reported as hazard ratios (HRs) or odds ratio $(\mathrm{OR})$ and $95 \%$ confidence intervals $(95 \% \mathrm{Cl})$. A $P$-value $<0.05$ (two-tailed) was considered statistically significant for all analyses. Statistical analyses were performed using SPSS 22.0 (IBM, Chicago, IL).

\section{3 | RESULTS}

\section{1 | Baseline characteristics}

Among 162 patients with dNETs, median patient age was 59 (IQR, 51-68) years and $53.7 \%(n=87)$ of patients were male (Table 1$)$. Roughly one-infive $(n=34 / 162,21.0 \%$ ) patients had a functional tumor; gastrinoma ( $n=31 / 34,91.2 \%$ ) was the predominant tumor type. The overwhelming majority of patients had no designated syndrome ( $n=146,90.1 \%$ ), whereas a small subset of individuals had multiple endocrine neoplasia type $1(n=8,4.9 \%)$ or neurofibromatosis syndrome $(n=4,2.5 \%)$. Abdominal pain (47.5\%) was the most common symptom. The majority ( $n=127,78.4 \%)$ of patients underwent an open surgical procedure. Surgical procedures included transduodenal resection $(n=25,15.4 \%)$, partial duodenectomy ( $n=20,12.3 \%)$, segmental duodenectomy $(n=33$, 20.4\%), and pancreaticoduodenectomy (PD) ( $n=52,32.1 \%) ; 30$ (18.5\%) patients underwent an endoscopic resection. Based on final pathological assessment, median tumor size was $1.2 \mathrm{~cm}$ (IQR, 0.7-2.0 cm). A total of 101 (62.3\%) patients underwent a concomitant lymphadenectomy (LND) at the time of surgery (transduodenal resection, $n=11$; partial duodenectomy, $n=14$; segmental duodenectomy, $n=26$; PD, $n=50$ ); median TNLE was 10 (IQR, 3-16). Among patients who underwent LND ( $n=101)$, at least one LNM was identified in 61 (60.4\%) patients. The overall incidence of procedure-related complications was $48.1 \%(n=78)$ with $22.8 \%(n=37)$ of patients experiencing a severe Clavien-Dindo III-V complication.

\section{2 | Periampullary versus nonampullary dNETs}

In assessing the cohort, 127 (78.4\%) patients had a dNET located in the duodenum away from ampulla of Vater, whereas 35 (21.6\%) 
TABLE 1 Clinicopathologic characteristics and surgical procedures

\begin{tabular}{|c|c|c|c|c|}
\hline & Overall $(n=162)$ & Periampullary dNETs $(n=35)$ & Nonampullary dNETs $(n=127)$ & P-value \\
\hline Age (y) & $59(51-68)$ & $56(50-70)$ & $59(52-68)$ & 0.559 \\
\hline Sex & & & & 0.340 \\
\hline Female & 75 (46.3\%) & $19(54.3 \%)$ & $19(54.3 \%)$ & \\
\hline Nonfunctional tumor & $128(79.0 \%)$ & 30 (85.7\%) & $98(77.2 \%)$ & 0.352 \\
\hline Functional tumor & $34(21.0 \%)$ & $5(14.3 \%)$ & $29(22.8 \%)$ & 0.326 \\
\hline Somatostatinoma & $2(1.2 \%)$ & $1(2.9 \%)$ & $1(0.8 \%)$ & \\
\hline Glucagonoma & $1(0.6 \%)$ & - & $1(0.8 \%)$ & \\
\hline Genetic syndrome & & & & 0.059 \\
\hline None & $146(90.1 \%)$ & 30 (85.7\%) & $116(91.3 \%)$ & \\
\hline MEN 1 & $8(4.9 \%)$ & $1(2.9 \%)$ & $7(5.5 \%)$ & \\
\hline Neurofibromatosis & $4(2.5 \%)$ & $3(8.6 \%)$ & $1(0.8 \%)$ & \\
\hline Clinical jaundice & $10(6.2 \%)$ & $8(22.9 \%)$ & $2(1.6 \%)$ & $<0.001$ \\
\hline Gastrointestinal bleeding & $21(13.0 \%)$ & $2(5.7 \%)$ & 19 (15.0\%) & 0.254 \\
\hline Diarrhea & $33(20.4 \%)$ & 7 (20.0\%) & $26(20.5 \%)$ & 1.000 \\
\hline Nausea/vomiting & $37(22.8 \%)$ & $11(31.4 \%)$ & $26(20.5 \%)$ & 0.182 \\
\hline Preoperative FNA & 47 (29.0\%) & $14(40.0 \%)$ & $33(26.0 \%)$ & 0.141 \\
\hline \multicolumn{5}{|l|}{ Primary location } \\
\hline D1 & $76(46.9 \%)$ & - & $76(59.8 \%)$ & \\
\hline $\mathrm{D} 2$ & $26(16.0 \%)$ & - & $26(20.5 \%)$ & \\
\hline $\mathrm{D} 1+\mathrm{D} 2$ & $7(4.3 \%)$ & - & $7(5.5 \%)$ & \\
\hline D3/D4 & $4(2.5 \%)$ & - & $4(3.1 \%)$ & \\
\hline Surgery technique & & & & 0.267 \\
\hline Segmental duodenectomy & $33(20.4 \%)$ & - & $33(26.0 \%)$ & \\
\hline Pancreaticoduodenectomy & 52 (32.1\%) & $21(60.0 \%)$ & $31(24.4 \%)$ & \\
\hline Operation time (min) & $200(138-306)$ & $250(154-375)$ & $196(133-302)$ & 0.082 \\
\hline Blood loss (mL) & $125(25-300)$ & $200(50-500)$ & $100(20-300)$ & 0.074 \\
\hline Surgical margin & & & & 1.000 \\
\hline RO & 131 (80.9\%) & 28 (80.0\%) & $103(81.1 \%)$ & \\
\hline R1 & $23(14.2 \%)$ & $5(14.3 \%)$ & $18(14.2 \%)$ & \\
\hline Largest tumor size $(\mathrm{cm})$ & $1.2(0.7-2.0)$ & $1.8(1.2-2.5)$ & $1.1(0.7-1.7)$ & 0.019 \\
\hline Tumor number & & & & 0.044 \\
\hline Single & $141(87.0 \%)$ & $34(97.1 \%)$ & 107 (84.3\%) & \\
\hline Multiple & $21(13.0 \%)$ & $1(2.9 \%)$ & $20(15.7 \%)$ & \\
\hline Lymphadenectomy & $101(62.3 \%)$ & $24(68.6 \%)$ & 77 (60.6\%) & 0.424 \\
\hline No. of lymph node examined & $10(3-16)$ & $15(11-21)$ & $7(2-15)$ & 0.005 \\
\hline Lymph nodes status & & & & 0.241 \\
\hline Negative & $40(39.6 \%)$ & 7 (29.2\%) & $33(42.9 \%)$ & \\
\hline Positive & $61(60.4 \%)$ & 17 (70.8\%) & $44(57.1 \%)$ & \\
\hline No. of positive lymph nodes & $2(1-4)$ & $4(2-6)$ & $2(1-3)$ & 0.285 \\
\hline
\end{tabular}


TABLE 1 (Continued)

\begin{tabular}{|c|c|c|c|c|}
\hline & Overall $(n=162)$ & Periampullary dNETs $(n=35)$ & Nonampullary dNETs $(n=127)$ & P-value \\
\hline WHO classification & & & & 0.104 \\
\hline G1 & $106(65.4 \%)$ & $22(62.9 \%)$ & $84(66.1 \%)$ & \\
\hline $\mathrm{G} 2$ & $51(31.5 \%)$ & $10(28.6 \%)$ & $22(32.3 \%)$ & \\
\hline G3 & 5 (3.1\%) & $3(8.6 \%)$ & $2(1.6 \%)$ & \\
\hline AJCC T stage & & & & 0.018 \\
\hline $\mathrm{T} 1$ & $56(34.6 \%)$ & $5(14.3 \%)$ & $51(40.2 \%)$ & \\
\hline $\mathrm{T} 4$ & $6(3.7 \%)$ & $2(5.8 \%)$ & 4 (3.1\%) & \\
\hline Lymph-vascular invasion & 31 (19.1\%) & $11(31.4 \%)$ & $20(15.7 \%)$ & 0.184 \\
\hline Perineural invasion & $12(7.4 \%)$ & $3(8.6 \%)$ & $9(7.1 \%)$ & 1.000 \\
\hline Postoperative morbidity & 78 (48.1\%) & $18(51.4 \%)$ & 60 (47.2\%) & 0.705 \\
\hline
\end{tabular}

Abbreviations: AJCC, American Joint Committee on Cancer; dNETs, duodenal neuroendocrine tumors; MEN 1, multiple endocrine neoplasia type 1.

FIGURE 1 A, overall survival of the whole cohort $(n=162)$; B, overall survival of patients with periampullary $(n=35)$ or nonampullary $(n=127)$ duodenal neuroendocrine tumors
(A)

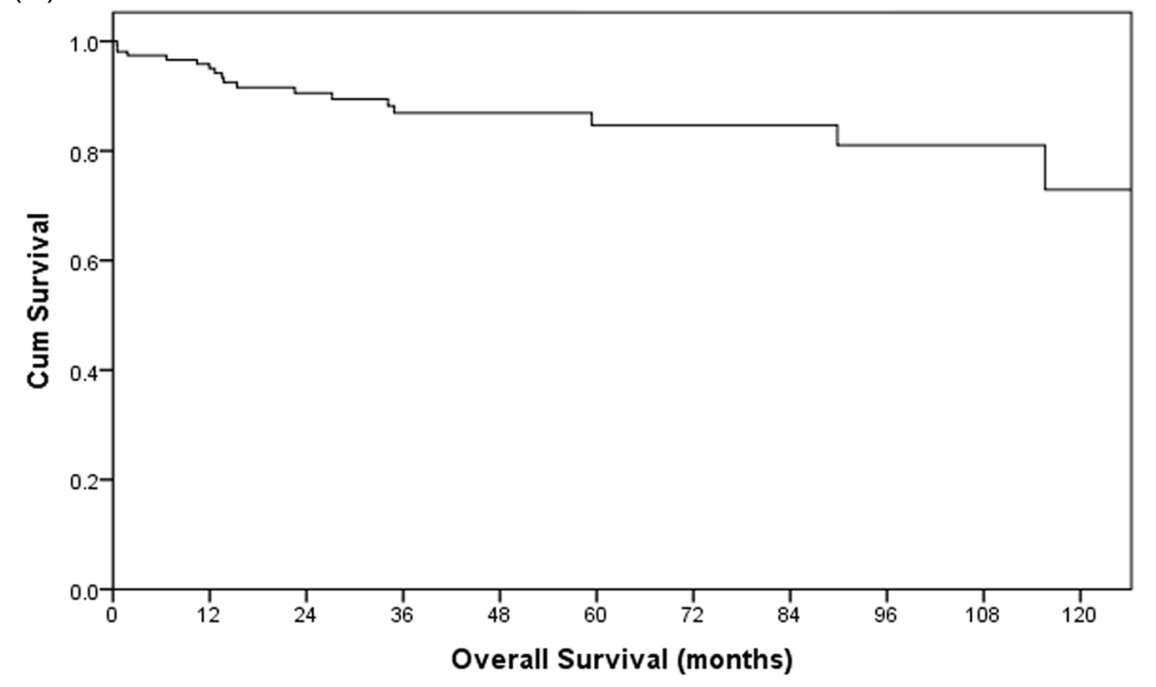

(B)

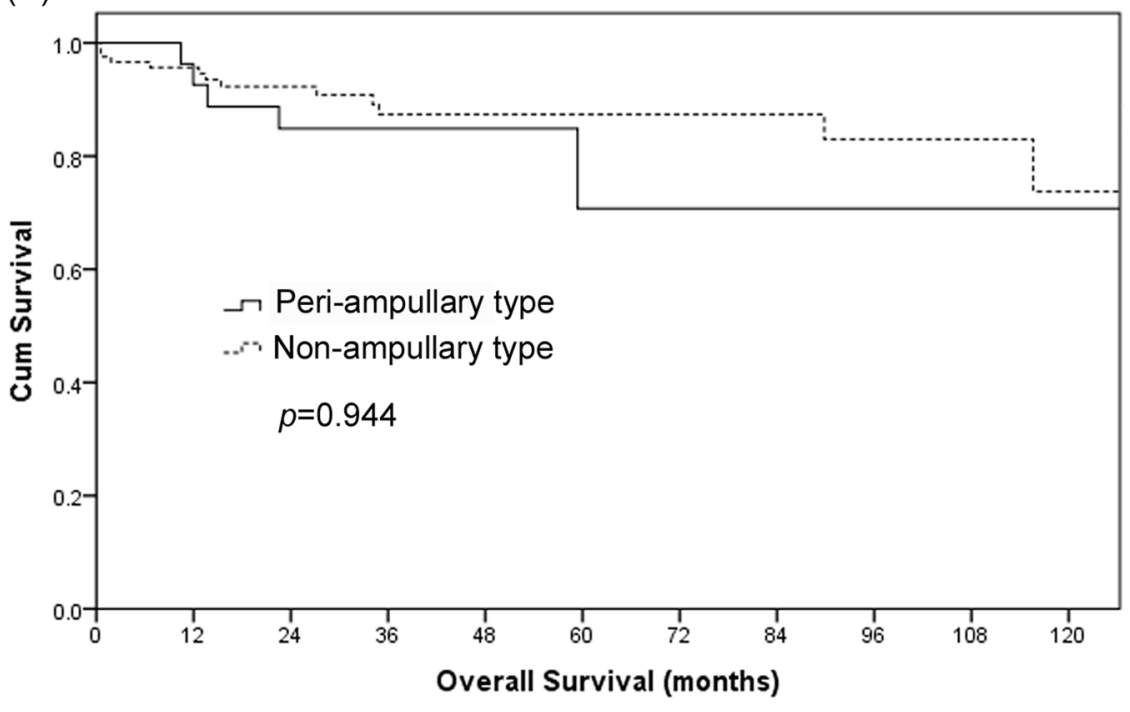


patients had a periampullary dNET. Clinicopathologic characteristics and surgical procedures associated with nonperi-ampullary and periampullary pNET tumors were largely comparable (Table 1). Perhaps not surprisingly, patients with periampullary dNETs were more likely to present with clinical jaundice $(22.9 \%$ vs $1.6 \%$; $P<.001)$ and abdominal pain $(68.6 \%$ vs $41.7 \% ; P=.007)$ versus patients with nonampullary dNETs. In addition, more patients who had a periampullary dNET underwent a PD $(n=21,60.0 \%)$ compared with only $24.4 \%(n=31)$ of patients with a nonampullary dNET $(P<.001)$. In turn, patients with a periampullary dNET had a higher TNLE compared with nonperi-ampullary dNET (median 15 vs 7, respectively; $P=.005$ )(Table 1 ). In addition, patients with periampullary dNETs were more likely to have a single tumor that was larger in size versus patients who had nonampullary tumors (both $P<.05$ ). In contrast, receipt of LND, as well as incidence and number of LNM, were not different among patients with ampullary versus nonampullary dNETs (Table 1).

\section{3 | Long-term survival}

With a median follow-up of 27.2 (IQR, 8.9-57.0) months, 1-, 3-, and 5year OS was $94.2 \%, 86.9 \%$, and $84.7 \%$, respectively (Figure $1 \mathrm{~A})$. Of note, OS was similar among patients with periampullary versus nonampullary dNETs (5-year OS, $70.8 \%$ vs $87.3 \%$; $P=.944$ ) (Figure 1B). In the subset of patients who underwent PD, OS was also comparable among patients with periampullary $(n=21)$ and nonampullary $(n=31)$ dNETs (5-year OS, $81.0 \%$ vs $82.0 \%$; $P=1.000$ ). On multivariable analysis, only G2/G3 WHO classification was associated with a higher risk of worse OS (Reference G1, HR, 1.5; $95 \% \mathrm{Cl}$, 1.0-2.1; $P=.032$ ). In contrast, tumor location, size, and number, American Joint Committee on Cancer (AJCC) T stages, nodal status, as well as treatment procedures were not associated with long-term survival of dNETs patients (Table 2 ).

Among the 18 (11.1\%) patients who developed tumor recurrence during follow-up, 9 (50\%) developed hepatic recurrence only, whereas 8 (44.4\%) patients developed loco-regional resection site and/or LN recurrence; one (5.6\%) patient had both locoregional and distant metastasis. Tumor recurrence was no different among patients with periampullary versus nonampullary dNETs or among patients undergoing different surgical procedures (both $P>0.05$ ).

\subsection{Tumor size and nodal metastasis}

As tumor size is a key indicator in defining the T category for dNETs in the AJCC staging manual, ${ }^{16}$ the impact of tumor size on the proportion of LND, as well as the incidence of nodal metastasis, was further analyzed. Of note, LND were performed among almost all (93.8\%) patients with dNET $>2 \mathrm{~cm}$ compared with $61.4 \%$ of patients with tumors of 1 to $2 \mathrm{~cm}$ and $52.2 \%$ of patients with tumors $\leq 1 \mathrm{~cm}$ (both $P<0.01$ ) (Figure $2 \mathrm{~A}$ ). Patients with larger tumors were also more likely to have a higher TNLE (median TNLE > $2 \mathrm{~cm} 14$ vs $1-2 \mathrm{~cm} 7 \mathrm{vs} \leq 1 \mathrm{~cm} \mathrm{5;} P<0.001$ ) (Figure $2 \mathrm{~b}$ ). In addition, the incidence of LNM incrementally increased among patients
TABLE 2 Factors associated with overall survival after curative resection for duodenal neuroendocrine tumors (dNETs)

\begin{tabular}{|c|c|c|c|c|}
\hline & \multicolumn{2}{|c|}{ Univariate analysis } & \multicolumn{2}{|c|}{ Multivariable analysis } \\
\hline & HR $(95 \% \mathrm{Cl})$ & $P$ value & HR $(95 \% \mathrm{Cl})$ & $P$ value \\
\hline Sex (male vs female) & $1.3(0.5-3.4)$ & 0.535 & & \\
\hline Functional status & $0.4(0.1-1.7)$ & 0.202 & & \\
\hline Symptomatic & $0.5(0.2-1.1)$ & 0.083 & & \\
\hline Genetic syndrome & $0.4(0.1-20.0)$ & 0.309 & & \\
\hline $\begin{array}{l}\text { AJCC T categories } \\
\text { T1 } \\
\text { T2 } \\
\text { T3-T4 }\end{array}$ & $\begin{array}{c}\text { Ref. } \\
0.8(0.3-2.9) \\
1.9(1.1-6.6)\end{array}$ & $\begin{array}{l}0.835 \\
0.024\end{array}$ & $\begin{array}{c}\text { Ref. } \\
0.4(0.1-1.7) \\
0.9(0.2-4.1)\end{array}$ & $\begin{array}{l}0.425 \\
0.924\end{array}$ \\
\hline Multiple lesions & $0.7(0.2-3.0)$ & 0.623 & & \\
\hline $\begin{array}{l}\text { Tumor size }(\mathrm{cm}) \\
\quad \leq 1 \\
1-2 \\
>2\end{array}$ & $\begin{array}{c}\text { Ref. } \\
0.9(0.3-2.5) \\
0.9(0.3-2.8)\end{array}$ & $\begin{array}{l}0.831 \\
0.913\end{array}$ & & \\
\hline $\begin{array}{l}\text { Tumor location } \\
\text { Duodenum } \\
\text { Ampulla of Vater }\end{array}$ & $\begin{array}{c}\text { Ref. } \\
1.0(0.7-1.4)\end{array}$ & 0.944 & & \\
\hline $\begin{array}{l}\text { Surgery technique } \\
\text { Endoscopic } \\
\text { Open/laparoscopic }\end{array}$ & $\begin{array}{c}\text { Ref. } \\
1.3(0.3-5.7)\end{array}$ & 0.732 & & \\
\hline $\begin{array}{l}\text { Surgical margin } \\
\text { R0 } \\
\text { R1 }\end{array}$ & $\begin{array}{c}\text { Ref. } \\
0.6(0.1-2.7)\end{array}$ & 0.537 & & \\
\hline $\begin{array}{l}\text { Lymphadenectomy } \\
\text { No } \\
\text { Yes }\end{array}$ & $\begin{array}{c}\text { Ref. } \\
0.9(0.4-2.3)\end{array}$ & 0.874 & & \\
\hline Nodal metastasis & $0.5(0.2-1.7)$ & 0.260 & & \\
\hline $\begin{array}{l}\text { WHO classification } \\
\text { G1 } \\
\text { G2/G3 }\end{array}$ & $\begin{array}{c}\text { Ref. } \\
1.7(1.1-3.2)\end{array}$ & 0.025 & $\begin{array}{c}\text { Ref. } \\
1.5(1.0-2.1)\end{array}$ & 0.032 \\
\hline $\begin{array}{l}\text { Lymph-vascular } \\
\text { invasion }\end{array}$ & $2.5(0.5-13.9)$ & 0.282 & & \\
\hline Perineural invasion & $2.6(0.4-15.6)$ & 0.296 & & \\
\hline
\end{tabular}

Abbreviation: $95 \% \mathrm{Cl}$, 95\% confidence intervals; AJCC, American Joint Committee on Cancer; HR, hazard ratio.

with tumors $\leq 1 \mathrm{~cm}, 1$ to $2 \mathrm{~cm}$ and $>2 \mathrm{~cm}$ (LNM, $40.0 \%$ vs. $65.7 \%$ vs. $80.0 \%, P=0.003$ ) (Figure $2 \mathrm{C}$ ).

The likelihood to identify LNM was associated with TNLE. Specifically, TNLE $\geq 8$ was associated with a higher incidence of identifying LNM (TNLE < 8: 20/45, 44.4\% vs. TNLE $\geq 8$ : 41/56, 73.2\%; $P=.004$ ), as well as a higher number of LNM identified (median number of LNM, TNLE $\geq 8$ : 2 [IQR, 1-5], vs TNLE < 8: 1 [IQR, 1-2], $P<0.001)$. In addition, TNLE $\geq 8$ had the highest discriminatory power relative to the incidence of LNM (area under the curve [AUC] 0.676 , sensitivity $67.2 \%$, specificity $=$ $65.0 \%$ ) (Figure 2D). On multivariable analysis, tumor size $(1-2 \mathrm{~cm}$ vs $\leq 1 \mathrm{~cm}$ (OR, 2.8; 95\%Cl, 1.0-8.0; $P=.048),>2 \mathrm{~cm}$ vs $\leq 1 \mathrm{~cm}(\mathrm{OR}$, 4.6; $95 \% \mathrm{Cl}, 1.4-15.0 ; P=0.012$ ), as well as TNLE $\geq 8$ vs $<8$ (OR, 3.6; $95 \% \mathrm{Cl}, 1.4-9.2 ; P=.007)$ were associated with the likelihood of identifying LNM (Table 3). 
(A)

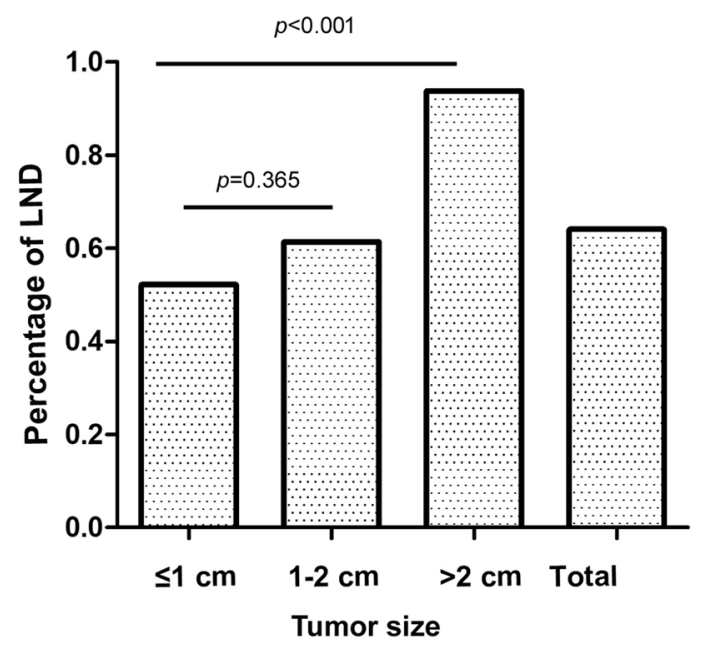

$\begin{array}{lllll}\text { Patient NO. } & & & & \\ \text { LND } & 35 & 35 & 30 & 100 \\ \text { Total } & 67 & 57 & 32 & 156\end{array}$

(C)

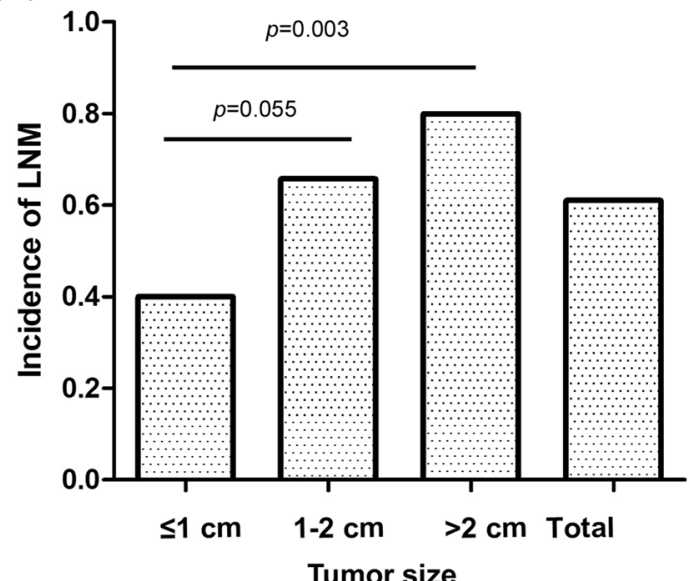

Patient NO,

$\begin{array}{lllcc}\text { LNM } & 14 & 23 & 24 & 61 \\ \text { Total } & 35 & 35 & 30 & 100\end{array}$

(B)

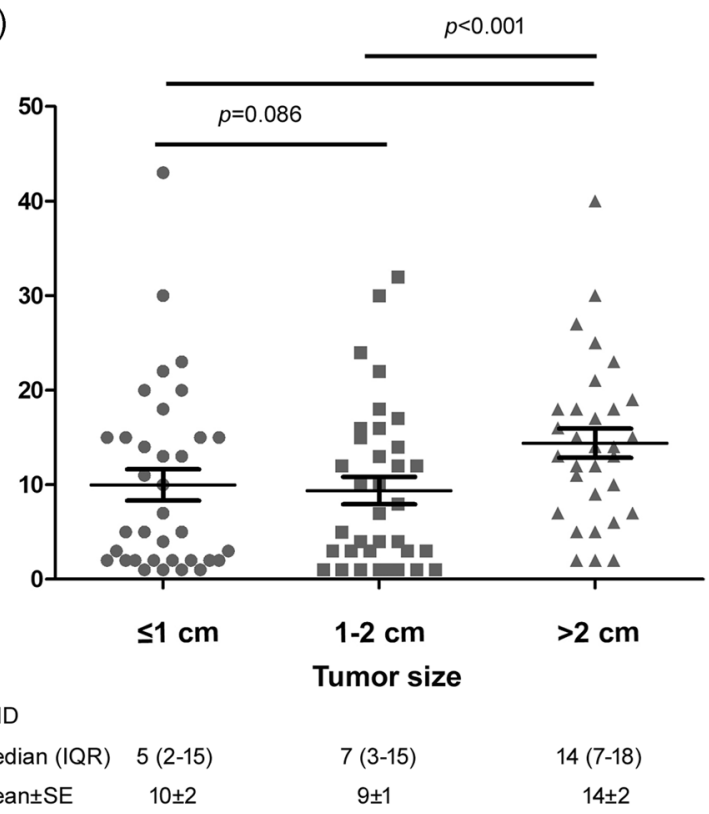

(D)

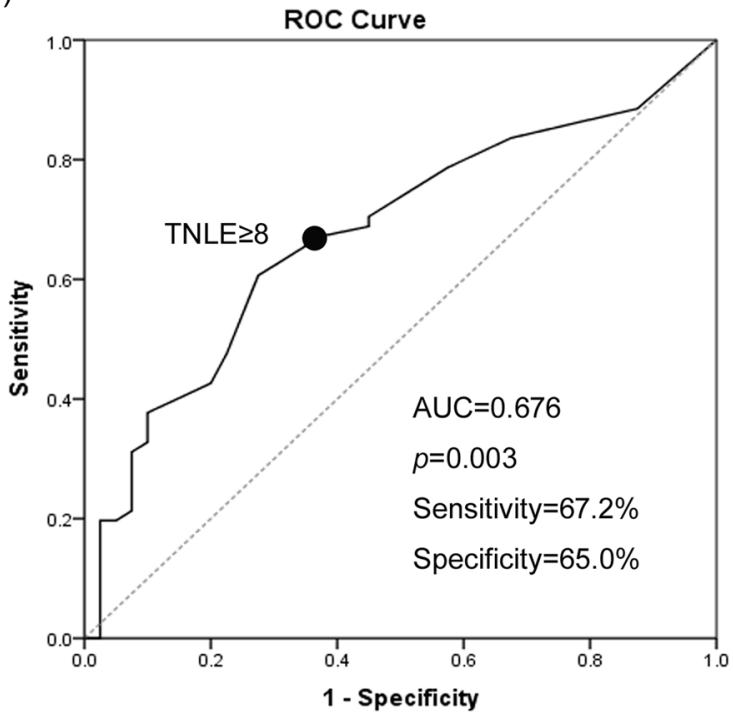

FIGURE 2 The proportion of lymphadenectomy (LND) (A) and number of LND (B) among patients with different tumor sizes. C, the incidence of lymph node metastasis (LNM) among patients with different tumor sizes. D, Receiver operative characteristics (ROC) analysis illustrating that total number of lymph nodes examined (TNLE) $\geq 8$ had the highest discriminatory power relative to LNM

\section{4 | DISCUSSION}

The AJCC TNM staging system for NET incorporates tumor size, nodal status, and distant metastasis to stratify outcomes of patients with dNETs. The impact of tumor size and nodal status on prognosis has, however, not been fully investigated, partially due to the rarity of this disease. The current study was important as we utilized a large multi-institutional database to demonstrate that long-term survival of patients with dNETs was comparable among patients with peri- or nonampullary dNETs. Rather than location or size, tumor grade G2/ $\mathrm{G} 3$ was the main risk factor associated with worse prognosis. Among patients who underwent LND, three out of five patients had at least one LNM. Perhaps not surprisingly, LND was utilized incrementally more often among patients who had larger dNETs $(\leq 1 \mathrm{~cm}, 52.2 \%$ vs $1-2 \mathrm{~cm}, 61.4 \%$ vs $>2 \mathrm{~cm}, 93.8 \%$ ) and the incidence of LNM also increased ( $\leq 1 \mathrm{~cm}, 40.0 \%$ vs $1-2 \mathrm{~cm}, 65.7 \%$ vs $>2 \mathrm{~cm}, 80.0 \%)$. We noted that the TNLE with the best discriminatory power to ensure adequate staging of the nodal basin was a TNLE $\geq 8$ (AUC, 0.676). In fact, on multivariable analysis, in addition to tumor size, TNLE $\geq 8$ vs $<8$ was independently associated with the likelihood of identifying LNM. Collectively, data from the current study serves to highlight that patients with dNET generally have a favorable prognosis, however, the incidence of LNM may be high. Tumor size was associated with LNM, especially among those patients with a dNET 
TABLE 3 Factors associated with lymph node metastasis (LNM) of duodenal neuroendocrine tumors (dNETs)

\begin{tabular}{|c|c|c|c|c|}
\hline & \multicolumn{2}{|c|}{ Univariate analysis } & \multicolumn{2}{|c|}{ Multivariable analysis } \\
\hline & OR $(95 \% \mathrm{Cl})$ & $P$ value & OR $(95 \% \mathrm{Cl})$ & $P$ value \\
\hline Sex (female vs male) & $2.5(1.1-5.6)$ & 0.030 & $2.6(1.0-6.4)$ & 0.046 \\
\hline \multicolumn{5}{|l|}{ Functional status } \\
\hline Symptomatic & $1.1(0.4-3.1)$ & 0.805 & & \\
\hline Genetic syndrome & $2.1(0.5-8.2)$ & 0.297 & & \\
\hline Multiple lesions & $1.3(0.4-4.2)$ & 0.626 & & \\
\hline $\begin{array}{l}\text { Tumor size }(\mathrm{cm}) \\
\quad \leq 1 \\
1 \text { to } 2 \\
>2\end{array}$ & $\begin{array}{c}\text { Ref. } \\
2.9(1.1-7.6) \\
6.0(2.0-18.4)\end{array}$ & $\begin{array}{l}0.033 \\
0.002\end{array}$ & $\begin{array}{c}\text { Ref. } \\
2.8(1.0-8.0) \\
4.6(1.4-15.0)\end{array}$ & $\begin{array}{l}0.048 \\
0.012\end{array}$ \\
\hline $\begin{array}{l}\text { Tumor location } \\
\text { Duodenum } \\
\text { Ampulla of Vater }\end{array}$ & $\begin{array}{c}\text { Ref. } \\
0.8(0.6-1.1)\end{array}$ & 0.819 & & \\
\hline $\begin{array}{l}\text { Total number of } \\
\text { LNs examined } \\
<8 \\
\geq 8\end{array}$ & $\begin{array}{c}\text { Ref. } \\
3.4(1.5-7.9)\end{array}$ & 0.004 & $\begin{array}{c}\text { Ref. } \\
3.6(1.4-9.2)\end{array}$ & 0.007 \\
\hline $\begin{array}{l}\text { WHO classification } \\
\text { G1 } \\
\text { G2/G3 }\end{array}$ & $\begin{array}{c}\text { Ref. } \\
1.8(0.6-5.7)\end{array}$ & 0.328 & & \\
\hline
\end{tabular}

Abbreviations: $95 \% \mathrm{Cl}, 95 \%$ confidence intervals; OR, odds ratio.

$>1 \mathrm{~cm}$, and the ability to identify LNM depended on the adequacy of the LND with TNLE $\geq 8$ being the optimal TNLE to stage patients with dNETs.

Duodenal NETs have been anatomically classified most often as periampullary versus nonampullary. Perhaps not surprisingly, periampullary tumor location was associated with higher likelihood of abdominal pain ( $80 \%$ vs $73 \%$ ) and clinical jaundice (22.9\% vs $1.6 \%$ ) versus nonampullary dNETs due to obstruction of bile and pancreatic ducts. Consistent with a previous population-based study, ${ }^{18}$ the current study also noted that periampullary dNETs were larger at the time of presentation compared with nonampullary dNETs. Patients with periampullary dNETs were also more likely to undergo PD and had a higher number of LNs examined than patients with nonampullary dNETs. The incidence of LNM was, however, no different among patients with periampullary versus nonampullary dNETs. Consistent with previous data, we also noted that tumor grade was associated with long-term survival among patients with both periampullary and nonampullary dNETs after curative resection. ${ }^{8}$ In contrast, Randle et $\mathrm{al}^{18}$ failed to find an association of higher tumor grade and worse survival among patients with dNETs-especially as related to patients who had periampullary versus nonampullary dNETs. The reason for these disparate results are likely multifactorial yet may be due to patients with periampullary dNET in the current study being more likely to undergo a more extensive resection, such as $\mathrm{PD}$, compared with patients included in the study by Randle et al ${ }^{18}$ who more often underwent a local excision.

Prognosis following curative-intent resection of dNET was generally very good with a 5 -year survival of $84.7 \%$, which was comparable with previous data reported in the literature $66 \%$ 93.8\%). ${ }^{8,19,20}$ Interesting, the impact of LNM on long-term outcome has been controversial. While some studies have suggested that LNM was associated with a worse prognosis, ${ }^{7,16}$ data from the current study, as well as several other previous reports, have not demonstrated an association of LNM with long-term prognosis. ${ }^{8,9,21}$ Given the low accuracy of preoperative imaging to detect LNM among dNETs patients, most surgeons advocate for routine LND at the time of surgical resection of dNETs. ${ }^{12,22}$ To this point, LNM was present in over one-half of all patients with dNETs (60.4\%). Perhaps of more interest, the data clearly demonstrated a strong correlation with dNET size and the likelihood of LNM, as patients with tumor $>2 \mathrm{~cm}$ (80.0\%) or 1 to $2 \mathrm{~cm}(65.7 \%)$ in size had a much higher incidence of LNM than patients with tumors $\leq 1 \mathrm{~cm}(40.0 \%)(P=.003)$. Margonis et $\mathrm{al}^{10}$ had similarly reported a higher incidence of LNM among NET tumors sized $>1.5 \mathrm{~cm},{ }^{10}$ while Burke et al noted a difference in the incidence of LNM using tumor size using $>2 \mathrm{~cm}$ as the cut-off. ${ }^{23}$ While $1 \mathrm{~cm}$ is currently used as the cut-off size to differentiate T1 from T2 in the AJCC staging manual, ${ }^{11,16}$ there was still a relatively high incidence of LNM even among patients with small tumors $(\leq 1 \mathrm{~cm}, 40.0 \%)$. Whereas surgical resection and lymphadenectomy has traditionally been recommended for only tumors $>1 \mathrm{~cm}$, data in the current study suggest that patients with dNETs $\leq 1 \mathrm{~cm}$ should also be considered for LND rather than local excision alone.

The minimal number of LNs needed to examine to achieve accurate staging of the nodal basin for patients with dNETs has not been defined in the latest NCCN guidelines. ${ }^{11,16}$ The topic of TNLE has been an area of interest for several other hepatopancreatic diseases. In fact, TNLE among patients with pancreatic and small bowel NETs relative to recurrence-free survival and overall survival has been examined by our group and others. ${ }^{15,24}$ Using a large multi-institutional database with external validation based on the surveillance, epidemiology, and end results (SEER) registry, we demonstrated that TNLE $\geq 8$ had the highest discriminatory power relative to recurrence-free and overall survival among patients with pNET who hadone to three LNM, and patients who had $\geq 4$ LNM in both a multi-institutional data set and the SEER database. ${ }^{15}$ In the current study, we similarly noted that TNLE $\geq 8$ had the strongest discriminatory power to ensure identification of possible LNM and optimally stage the nodal basin for patients with dNETs. Specifically, TNLE $\geq 8$ versus TNLE $<8$ was associated with a higher chance of identifying LNM (73.2\% vs $44.4 \%$ ), as well as a higher number of LNM identified. Taken together, LND as part of an operative procedure for patients with dNET should include examination of $\geq 8 \mathrm{LN}$ to ensure adequate staging.

Several limitations should be considered when interpreting data in the current study. While a multi-institutional study increased the sample size of the analytic cohort, patient selection, surgical technique, as well as utilization of LND and pathologic examination of $\mathrm{LN}$, may have varied at different centers. All participatory centers were, however, major hepatopancreatic institutions that followed standard state-of-the-art care guidelines regarding the management of patients with NET. The current study also did not note a difference of long-term survival among patients with versus without LNM. The 
reason for this may have been due to a lack of statistic power (Type II error); however, other authors have noted a similar finding and attributed the lack of prognostic impact to the indolent nature of dNET and the very good overall prognosis. ${ }^{8,9,21}$ The current study also only included patient who underwent curative-intent resection and therefore patients receiving nonsurgical treatments were not available for comparison.

In conclusion, patients with a dNET had an overwhelmingly favorable prognosis after curative-intent resection, despite the relatively high incidence of associated LNM. While the incidence of LNM directly correlated with tumor size, even patients with dNET $\leq 1 \mathrm{~cm}$ had a $40 \%$ incidence of LNM. Regional lymphadenectomy of at least eight LN was recommended to stage patients accurately. Interestingly, the presence of LNM was not, however, associated with long-term survival; rather, tumor grade was the factor that impacted prognosis. Collectively, data from the current study should help to inform the care of patients with dNETs.

\section{ACKNOWLEDGMENT}

Xu-Feng Zhang and Xiao-Ning Wu were supported by the Clinical Research Award of the First Affiliated Hospital of the Xi'an Jiaotong University of China (No. XJTU1AF-CRF-2017-004).

\section{CONFLICT OF INTERESTS}

The authors declare that they have no conflict of interests.

\section{US NEUROENDOCRINE TUMOR STUDY GROUP MEMBERS}

Alexandra G. Lopez-Aguiar MD: Division of Surgical Oncology, Department of Surgery, Winship Cancer Institute, Emory University, Atlanta, GA; Eleftherios Makris MD: Department of Surgery, Stanford University, Palo Alto, CA; Zaheer Kanji MD: Department of Surgery, Virginia Mason Medical Center, Seattle, WA; Alexander Fisher MD: Department of Surgery, University of Wisconsin School of Medicine and Public Health, Madison, WI; Bradley A. Krasnick MD: Department of Surgery, Washington University School of Medicine, St. Louis, WI; Paula M. Smith MD: Division of Surgical Oncology, Department of Surgery, Vanderbilt University, Nashville, TN; Megan Beems MD: Division of Hepatopancreatobiliary and Advanced Gastrointestinal Surgery, Department of Surgery, University of Michigan, Ann Arbor, MI.

\section{DATA AVAILABILITY STATEMENT}

The data that support the findings of this study are available from the corresponding author upon reasonable request.

\section{ORCID}

Xu-Feng Zhang (D) http://orcid.org/0000-0002-4483-7326 Diamantis I. Tsilimigras (D) http://orcid.org/0000-0002-3676-9263 Timothy M. Pawlik (D) http://orcid.org/0000-0002-7994-9870

\section{REFERENCES}

1. O'Toole D, Delle Fave G, Jensen RT. Gastric and duodenal neuroendocrine tumours. Best Pract Res Clin Gastroenterol. 2012;26: 719-735.

2. Jensen RT, Rindi G, Arnold R, et al. Well-differentiated duodenal tumor/carcinoma (excluding gastrinomas). Neuroendocrinology. 2006; 84:165-172.

3. Modlin IM, Lye KD, Kidd M. Carcinoid tumors of the stomach. Surg Oncol. 2003;12:153-172.

4. Modlin IM, Lye KD, Kidd M. A 5-decade analysis of 13,715 carcinoid tumors. Cancer. 2003;97:934-959.

5. Fitzgerald TL, Dennis SO, Kachare SD, Vohra NA, Zervos EE. Increasing incidence of duodenal neuroendocrine tumors: incidental discovery of indolent disease? Surgery. 2015;158:466-471.

6. Yao JC, Hassan M, Phan A, et al. One hundred years after "carcinoid": epidemiology of and prognostic factors for neuroendocrine tumors in 35,825 cases in the United States. J Clin Oncol. 2008;26:3063-3072.

7. Masui T, Sato A, Nakano K, et al. Comparison of recurrence between pancreatic and duodenal neuroendocrine neoplasms after curative resection: a single-institution analysis. Ann Surg Oncol. 2018;25:528-534.

8. Dogeas E, Cameron JL, Wolfgang $\mathrm{CL}$, et al. Duodenal and ampullary carcinoid tumors: size predicts necessity for lymphadenectomy. J Gastrointest Surg. 2017;21:1262-1269.

9. Untch BR, Bonner KP, Roggin KK, et al. Pathologic grade and tumor size are associated with recurrence-free survival in patients with duodenal neuroendocrine tumors. J Gastrointest Surg. 2014;18:457462. discussion 62-3.

10. Margonis GA, Samaha M, Kim Y, et al. A Multi-institutional analysis of duodenal neuroendocrine tumors: tumor biology rather than extent of resection dictates prognosis. J Gastrointest Surg. 2016;20:1098-1105.

11. Delle Fave G, O'Toole D, Sundin A, et al. ENETS consensus guidelines update for gastroduodenal neuroendocrine neoplasms. Neuroendocrinology. 2016;103:119-124.

12. Rossi RE, Rausa E, Cavalcoli F, Conte D, Massironi S. Duodenal neuroendocrine neoplasms: a still poorly recognized clinical entity. Scand J Gastroenterol. 2018;53:835-842.

13. Massironi S, Campana D, Partelli S, et al. Heterogeneity of duodenal neuroendocrine tumors: an italian multi-center experience. Ann Surg Oncol. 2018;25:3200-3206.

14. Dasari BVM, Al-Shakhshir S, Pawlik TM, et al. Outcomes of surgical and endoscopic resection of duodenal neuroendocrine tumours (NETs): a systematic review of the literature. J Gastrointest Surg. 2018;22:1652-1658.

15. Zhang XF, Xue F, Dong DH, et al. New nodal staging for primary pancreatic neuroendocrine tumors: a multi-institutional and national data analysis. Ann Surg. 2019. [published online ahead of print July 26 , 2019].

16. Amin MB. American Joint Committee on Cancer. New York: Springer; 2017.

17. Crippa S, Partelli S, Boninsegna L, Falconi M. Implications of the new histological classification (WHO 2010) for pancreatic neuroendocrine neoplasms. Ann Oncol. 23, 2012:1928.

18. Randle RW, Ahmed S, Newman NA, Clark CJ. Clinical outcomes for neuroendocrine tumors of the duodenum and ampulla of Vater: a population-based study. J Gastrointest Surg. 2014;18:354-362.

19. Milanetto AC, Pasquali C, Da Broi M, Brambilla T, Capretti G, Zerbi A. Ampullary neuroendocrine neoplasms: surgical experience of a rare and challenging entity. Langenbecks Arch Surg. 2018;403:581-589.

20. Kachare SD, Liner KR, Vohra NA, Zervos EE, Fitzgerald TL. A modified duodenal neuroendocrine tumor staging schema better defines the risk of lymph node metastasis and disease-free survival. Am Surg. 2014;80:821-826.

21. Burke CA, Beck GJ, Church JM, van Stolk RU. The natural history of untreated duodenal and ampullary adenomas in patients with familial 
adenomatous polyposis followed in an endoscopic surveillance program. Gastrointest Endosc. 1999;49:358-364.

22. Iwasaki T, Nara S, Kishi Y, Esaki M, Shimada K, Hiraoka N. Surgical treatment of neuroendocrine tumors in the second portion of the duodenum: a single center experience and systematic review of the literature. Langenbecks Arch Surg. 2017;402:925-933.

23. Burke AP, Sobin LH, Federspiel BH, Shekitka KM, Helwig EB. Carcinoid tumors of the duodenum. A clinicopathologic study of 99 cases. Arch Pathol Lab Med. 1990;114:700-704.

24. Zaidi MY, Lopez-Aguiar AG, Dillhoff M, et al. Prognostic role of lymph node positivity and number of lymph nodes needed for accurately staging small bowel neuroendocrine tumors. JAMA Surg. 2018;154:134-140.

How to cite this article: Zhang X-F, Wu X-N, Tsilimigras DI, et al. Duodenal neuroendocrine tumors: Impact of tumor size and total number of lymph nodes examined. J Surg Oncol.

2019;120:1302-1310. https://doi.org/10.1002/jso.25753 